\title{
Visual Field Compromised In Patients Suffering From Severe Menorrhagia
}

\section{Jennifer Wei Huen Shum ${ }^{1}$, Bonnie Nga Kwan Choy ${ }^{1}$, Jonathan Cheuk Hung Chan ${ }^{1}$, Wing Lau Hoㄹ, Bin} Yan Jiang ${ }^{3}$, Wai Ki Choi ${ }^{4}$, Vincent Y.T Cheung ${ }^{4}$, Jimmy S.M. Lai ${ }^{1{ }^{* *}}$

${ }^{1}$ Department of Ophthalmology, the University of Hong Kong, Hong Kong

${ }^{2}$ Department of Ophthalmology, Queen Mary Hospital, Hong Kong, Hong Kong

${ }^{3}$ Department of Applied Mathematics, Hong Kong Polytechnic University, Hong Kong

${ }^{4}$ Department of Obstetrics \& Gynaecology, Queen Mary Hospital, the University of Hong Kong

${ }^{\star}$ Corresponding author: Jimmy Lai, Department of Ophthalmology, The University of Hong Kong, Room 301, Block B, Cyberport 4, 100 Cyberport Road, Hong Kong, Tel: (852) 3962 1413; Email: laism@hku.hk

Received Date: April 17, 2017; Accepted Date: May 25, 2017; Published Date: May 27, 2017

Citation: Jennifer Wei Huen, Shum et al. (2017) Visual Field Compromised In Patients Suffering From Severe Menorrhagia. J Ophthalmol Open Access 1: 1-7

\author{
Abstract \\ Purpose: To evaluate menorrhagia as a risk factor for compromised visual field \\ Design: A cross-sectional cohort study \\ Participants: 25 Menorrhagic patients and 23 non-menorrhagic female subjects
}

Methods: Patients were recruited from the Obstetrics and Gynaecology clinic and divided into two groups. Those suffering from active menorrhagia were allocated into the disease group while those had never suffered from menorrhagia constituted the control group. All subjects completed a pictorial blood assessment chart (PBAC) to quantify the severity of their menorrhagia. All subjects then underwent an eye examination and investigations including visual field and optical coherent tomography.

Main Outcome Measures: The mean PBAC was compared between the disease group and the control group. Correlation analysis was tested between PBAC and visual field global indices.

Results: Subjects suffering from menorrhagia have a compromised performance in visual field when compared with subjects with no menorrhagia. A positive association was observed between the severity of menorrhagia and a poorer visual field performance.

Conclusions: Menorrhagia may be a risk factor for visual field defects. Further research is encouraged to evaluate whether it may be a risk factor for glaucoma development or progression.

Keywords: Visual field; Menorrhagia; Glaucoma; Reperfusion injury; Vascular factors

Synopsis: Subjects suffering from menorrhagia have a compromised performance in visual field when compared with subjects with no menorrhagia. A positive association was observed between the severity of menorrhagia and a poorer visual field performance. 


\section{Introduction}

Glaucoma arises from accelerated apoptosis of retinal ganglion cell (RGC) axons, resulting in an optic neuropathy with specific optic nerve (ON) head and visual field damages. While increased intraocular pressure (IOP) is a major risk factor, increasing evidence point towards haemodynamic disturbance and neurovascular coupling playing a major role as well.

Two main theories for glaucoma pathogenesis have been described. The mechanical theory stresses that increased IOP places mechanical shear and damage on RGC axons. The vascular theory implies insufficient ocular blood supply precedes glaucomatous damage, and is the result of either an increased IOP or factors that reduce ocular blood flow $[1,2]$. Ocular blood flow is reduced in glaucoma patients, including the iris, retina, optic nerve and choroid $[1,3]$. Nocturnal blood pressure dips and reduced diastolic pressure have been shown to be risk factors for glaucoma progression or development $[4,5]$.

These vascular risk factors are even more pronounced in normal tension glaucoma (NTG) patients, where an allegedly "normal" IOP range is already sufficient to produce glaucomatous damage [6-8]. Circadian fluctuation of the mean ocular perfusion pressure is a consistent risk factor for NTG, [9] contributing to the fluctuation theory, which emphasizes the role of diurnal IOP fluctuations in NTG progression. Another theory emphasizes different thresholds of vulnerability to IOP levels among different individuals [10].

While a high IOP is a predominant factor in producing glaucomatous damage in high tension glaucoma, vascular factors are more predominant in producing damage in NTG. It is logical that these different mechanisms may be responsible for the different patterns of visual field (VF) defect observed. When compared with high tension glaucoma, VF defects in NTG are relatively more localized and closer to fixation, and may be more predominant in the lower hemifield [11]. Inferior nasal visual field defect and inferior altitudinal visual field defect is a characteristic field defect in nonarteritic anterior ischemic optic neuropathy (NAION) [12]. Other factors like haemodialysis and shock have also been found to produce VF changes, with VF improvements immediately after haemodialysis $[13,14]$.

Blood flow instability not only leads to hypoperfusion but repeated mild reperfusion injury. An unstable oxygen supply leads to oxidative stress, where the formation of reactive oxygen species (ROS) damages mitochondria of RGC axons and the $\mathrm{ON}$ head [3]. If neighboring astrocytes are activated by either mechanical or ischemic stress, nitric oxide molecules will be produced, resulting in further formation of ROS. These ROS diffuses within axons in the retina and lateral geniculate nucleus to induce further apoptosis.
We see a similar unstable perfusion setting that may lead to dysfunctional regulation of ocular blood flow in patients with menorrhagia, where the systemic blood pressure may be transiently reduced in a cyclical fashion throughout each menstrual period [15]. However, the pattern and nature of hypoperfusion in menorrhagia differs from that of NTG and NAION. The authors thus suspect that menorrhagia may give rise to a visual field anomaly different from those observed in NTG and NAION. In this study, we set out to look into whether ON, retinal nerve fiber layer (RNFL) and VF anomalies exist among patients with menorrhagia.

\section{Methods}

This study adhered to the tenets of the Declaration of Helsinki. It has been approved by the Institutional Review Board of the University of Hong Kong/Hospital Authority Hong Kong West Cluster. The subjects' informed consent were obtained and recruited at the Obstetrics and Gynaecology Department and the study was conducted at the Ophthalmology Department in a tertiary teaching hospital between February 2014 and December 2015. This was a cross sectional cohort study.

Women suffering from ongoing menorrhagia being followed up at the gynecology clinic comprised of the disease group, while those following for other gynaecological conditions with no past history of menorrhagia comprised of the control group. The severity of menorrhagia was assessed and quantified by a pictorial blood assessment chart (PBAC) developed by Higham et al.[16] The definition of menorrhagia is defined as blood loss of $>80 \mathrm{~mL}$ [17]. It has been shown that a PBAC score of $>/=150$ correlates well with $>80 \mathrm{~mL}$ menstrual blood loss as estimated by the alkaline haematin method. 18 PBAC was either taken at the time of recruitment if the subject happened to be menstruating, or via telephone when the subject has her next cycle. Other inclusion criteria include an open angle on gonioscopy. Exclusion criteria included patients with pre-existing glaucoma, closed angles on gonioscopy, patients with preexisting ophthalmological diseases that would affect VF or optical coherence tomography (OCT) analysis, high myopia more than -8 diopters, patients with gynaecological malignancy, known anaemia due to causes other than menorrhagia and bleeding disorders with haemoglobin levels less than $10 \mathrm{~g} / \mathrm{dl}$.

Consenting subjects were referred to the Ophthalmology outpatient clinic and examined by 2 investigators (JS and BC). Baseline information collected included the patient's age and family history of glaucoma. Examinations performed included slit lamp examination, IOP measurement by Goldmann applanation, gonioscopy and assessment of the optic nerve and cup-disc ratio (CDR). Parameters recorded and investigations conducted by optometrist included visual acuity measurement measurement by Snellen chart, automated refraction, central corneal thickness (CCT), VF test (central 242, Humphrey Field Analyzer) and peripapillary retinal nerve fiber layer (RNFL) thickness (Spectralis spectral-domain optical coherence tomography, Heidelberg Engineering, Heidelberg, Germany). 
PBAC score were calculated for all subjects. For patients in the disease group, if they required hospital admission for blood transfusion, data was also collected for haemoglobin and ferritin levels prior to transfusion.

\section{Statistical Analysis}

Statistical calculation was performed by a statistician. Only data from the patient's left eye were analyzed to avoid statistical overestimation due to inter-eye correlation. Using Shapiro-Wilk test for pattern standard deviation (PSD), a $\mathrm{p}$ value of $1.355 \mathrm{e}-05$ was obtained, therefore normality assumption is violated.

Statistical calculation was performed by a statistician. Only data from the patient's left eye were analyzed to avoid statistical overestimation due to inter-eye correlation. Using Shapiro-Wilk test for pattern standard deviation (PSD), a $\mathrm{p}$ value of $1.355 \mathrm{e}-05$ was obtained, therefore normality assumption is violated.

For secondary outcome, we also looked for correlation between VF global indices, OCT indices and the severity of menorrhagia, as reflected by the PBAC score. Pearson's correlation test was used.

\section{Results}

Twenty-six subjects were recruited into the disease group and 24 subjects were recruited into the control group. One subject was excluded from data analysis from each of the 2 groups due to spherical equivalent showing high myopia more than -8 diopters, which may interfere with VF and OCT interpretation. Twenty-five eyes from the disease group and 23 eyes from the control group were available for analysis. Among the control group, 14 subjects have already entered menopause and PBAC score was then taken as zero.

The difference in mean PBAC of the disease group and control group was statistically significant, being $1815+/$ 1944 for the disease group and $35.3+/-49.6$ for the control group respectively. $(\mathrm{p}<0.0001)$ In the disease group, the average duration of active menorrhagia was 2.6 years. However, this data cannot be recalled in 8 subjects. Twenty-three subjects from the disease group required blood transfusion for their severe menorrhagia, and thus pre-transfusion ferritin and haemoglobin levels were taken.

The mean age, CCT and spherical equivalent were comparable between the disease group and control group. The mean age for the disease group was $45.04+/-7.37$, while that for the control group was $48.39+/-6.61(\mathrm{p}=0.10$, unpaired $\mathrm{t}$ test. The mean CCT for the disease group and control group were $548.3+/$ - 26.1 um and $548.9+/$ - 26.1 um respectively ( $\mathrm{p}=0.9$, unpaired t-test). The mean spherical equivalent for the disease group is $-1.7+/-1.7 \mathrm{D}$ while that for the control group was $-1.9+/-2.7 \mathrm{D}$ ( $\mathrm{p}=0.8$, unpaired t-test). Two patients from the disease group and 4 patients from the control group had family history of glaucoma ( $\mathrm{p}=0.33$, chi square test). Baseline demographic data and menorrhagia parameters are tabulated in Table $1 \mathrm{a}$ and Table $1 \mathrm{~b}$.
Table 1: Table showing baseline data for study subjects

\begin{tabular}{|c|c|c|c|}
\hline & $\begin{array}{l}\text { Disease } \\
\text { group }(n=25)\end{array}$ & $\begin{array}{l}\text { Control } \\
\text { group }(n=23)\end{array}$ & $\mathrm{p}$ value \\
\hline Mean age & $45+/-7$ & $48+/-6$ & 0.1 \\
\hline $\begin{array}{l}\text { Family his- } \\
\text { tory of glau- } \\
\text { coma }\end{array}$ & 2 & 4 & $0.33 \#$ \\
\hline Gonioscopy & Open & Open & \\
\hline $\begin{array}{l}\text { Spherical } \\
\text { equivalent } \\
\text { (dioptre) }\end{array}$ & $-1.7+/-1.7$ & $-1.9+/-2.7$ & 0.8 \\
\hline $\begin{array}{l}\text { Central cor- } \\
\text { neal thick- } \\
\text { ness (um) }\end{array}$ & $548+/-26$ & $548+/-26$ & 0.9 \\
\hline IOP (mmHg) & $15+/-3$ & $14+/-2$ & 0.4 \\
\hline CDR & 0.3 & 0.3 & 1.0 \\
\hline PBAC & $\begin{array}{l}1815+/- \\
1944\end{array}$ & $35.3+/-49.6$ & $<0.0001$ \\
\hline $\begin{array}{l}\text { Menorrhagia } \\
\text { duration } \\
\text { (years) }\end{array}$ & 2.6 & NA & \\
\hline $\begin{array}{l}\text { Ferritin (ng/ } \\
\text { mL) }\end{array}$ & $\begin{array}{l}44.05+/- \\
48.3(n=23)\end{array}$ & NA & \\
\hline $\begin{array}{l}\text { Pre-transfu- } \\
\text { sion Hb (g/ } \\
\text { dl) }\end{array}$ & $\begin{array}{l}8.04+/-1.97 \\
(n=23)\end{array}$ & NA & \\
\hline
\end{tabular}

n, number; IOP, intraocular pressure, $\mathrm{CDR}$, cup-disc ratio; $\mathrm{PBAC}$, pictorial blood assessment chart; $\mathrm{Hb}$, haemoglobin; NA, not applicable

\#chi-squared test

Our results indicate that the VF was worse for the disease group when compared with control group. A significant difference was found between the mean PSD of the disease and control group. The mean PSD value was $2.73+/-1.89$ and $1.81+/-0.42$ for the disease and control group respectively $(\mathrm{p}<0.01)$. No significant differences were found for the mean MD, VFI or average RFNL thickness. (see Table 2)

Correlation analysis shows that a more severe menorrhagia is associated with a worse visual field. Pearson's correlation analysis shows a negative correlation between MD and PBAC and between VFI and PBAC, while a positive correlation between PD and PBAC was observed. This correlation pattern was seen both when all subjects were analyzed and when the disease group was analyzed. Statistical significance was also reached when analyzing all subjects and the disease group, but not within the control group. The correlation coefficient for subjects and subgroup analysis is shown in Table 3. The scatter plots with least square fit for the patient group is shown in Figure 1 and those for all subjects are shown in Figure 2 . 
Table 2: Table comparing the mean visual field global indices and average NFL thickness in the disease group and control group

\begin{tabular}{|l|l|l|l|}
\hline & $\begin{array}{l}\text { Disease } \\
\text { group }(\mathrm{n}=25)\end{array}$ & $\begin{array}{l}\text { Control } \\
\text { group }(\mathrm{n}=23)\end{array}$ & p value \\
\hline PSD & $2.73+/-1.9$ & $1.82+/-0.42$ & $<0.01$ \\
\hline MD & $-3.0+/-3.3$ & $\begin{array}{l}-2.28+/- \\
1.26\end{array}$ & 0.35 \\
\hline VFI & $95.64+/-7.5$ & $97.4+/-1.9$ & 0.34 \\
\hline NFL & $\begin{array}{l}105.6+/- \\
11.4\end{array}$ & $\begin{array}{l}103.8+/- \\
10.0\end{array}$ & 0.57 \\
\hline
\end{tabular}

n, number; PSD, pattern standard deviation; MD, mean deviation; VFI, visual field index; NFL, average nerve fiber layer thickness

Table 3: Table tabulating the correlation coefficient calculated using Pearson's correlation analysis

\begin{tabular}{|c|c|c|c|}
\hline & $\begin{array}{l}\text { All subjects } \\
(\mathrm{n}=48)\end{array}$ & $\begin{array}{l}\text { Disease } \\
\text { group }(n= \\
25)\end{array}$ & $\begin{array}{l}\text { Control } \\
\text { group } \\
(n=23)\end{array}$ \\
\hline PSD against $\mathrm{PBAC}$ & $\begin{array}{l}0.63 \\
(<0.0001)\end{array}$ & $\begin{array}{l}0.60 \\
(0.009)\end{array}$ & $\begin{array}{l}-0.28 \\
(0.22)\end{array}$ \\
\hline $\begin{array}{l}\text { Correlation coef- } \\
\text { ficient } \\
\text { ( } \mathrm{p} \text { value) }\end{array}$ & & & \\
\hline $\begin{array}{l}\text { MD against PBAC } \\
\text { Correlation coef- } \\
\text { ficient } \\
\text { ( } \mathrm{p} \text { value) }\end{array}$ & $\begin{array}{l}-0.61 \\
(0.001)\end{array}$ & $\begin{array}{l}-0.68 \\
(0.003)\end{array}$ & $\begin{array}{l}0.46 \\
(0.04)\end{array}$ \\
\hline $\begin{array}{l}\text { VFI against PBAC } \\
\text { Correlation coef- } \\
\text { ficient } \\
\text { (p value) }\end{array}$ & $\begin{array}{l}-0.61 \\
(0.003)\end{array}$ & $\begin{array}{l}-0.65 \\
(0.009)\end{array}$ & $\begin{array}{l}0.22 \\
(0.35\end{array}$ \\
\hline $\begin{array}{l}\text { NFL against PBAC } \\
\text { Correlation coef- } \\
\text { ficient } \\
\text { ( } \mathrm{p} \text { value) }\end{array}$ & $\begin{array}{l}-0.17 \\
(0.27)\end{array}$ & $\begin{array}{l}-0.33 \\
(0.11)\end{array}$ & $\begin{array}{l}0.02 \\
(0.93)\end{array}$ \\
\hline
\end{tabular}

n, number; PSD, pattern standard deviation; PBAC, pictorial blood assessment chart; MD, mean deviation; VFI, visual field index; NFL, average nerve fiber layer thickness

A subgroup analysis within the control group was done, comparing the VF global indices and OCT indices between patients with normal menses and those who have entered menopause. No statistical significance was seen. (see Table 4)
Table 4: Table comparing the mean VF indices and NFL thickness between subjects with normal menses and subjects with menopause

\begin{tabular}{|l|l|l|l|}
\hline & $\begin{array}{l}\text { Normal } \\
\text { menses } \\
(\mathrm{n}=9)\end{array}$ & $\begin{array}{l}\text { Menopause } \\
(\mathrm{n}=14)\end{array}$ & $\mathrm{p}$ value \\
\hline PSD & $1.66+/-0.44$ & $1.95+/-0.38$ & 0.15 \\
\hline MD & $\begin{array}{l}-1.66+/- \\
1.33\end{array}$ & $\begin{array}{l}-2.79+/- \\
0.97\end{array}$ & 0.06 \\
\hline VFI & $97.8+/-1.8$ & $97.1+/-2.0$ & 0.45 \\
\hline NFL & $\begin{array}{l}104.8+/- \\
10.5\end{array}$ & $\begin{array}{l}103.2+/- \\
10.1\end{array}$ & 0.72 \\
\hline
\end{tabular}

n, number; PSD, pattern standard deviation; PBAC, pictorial blood assessment chart; MD, mean deviation; VFI, visual field index; NFL, average nerve fiber layer thickness

\section{Discussion}

Our results demonstrate that subjects with severe menorrhagia had a compromised baseline VF compared to control, and also that more severe menorrhagia is associated with a poorer VF performance.

Although correlation analysis did not reach statistical significance among the control group, this is likely due to the fact that PBAC was taken as 0 for all menopause subjects, regardless of their previous menstrual flow. As our premise was that menorrhagia would lead to blood flow instability and thus may be a risk factor for visual field defect, all subjects without menorrhagia (both normal menses and menopause) were included in the correlation analysis. We do note that menopause subjects constitute the majority of the control group, and thus we have repeated the correlation analysis, this time excluding all menopause subjects. Results are shown in Table 5.

Table 5: Table tabulating the correlation coefficient calculated using Pearson's correlation analysis, with menopause subjects excluded

\begin{tabular}{|l|l|l|}
\hline & $\begin{array}{l}\text { All subjects }(\mathrm{n}= \\
34)\end{array}$ & $\begin{array}{l}\text { Control group }(\mathrm{n}= \\
9)\end{array}$ \\
\hline $\begin{array}{l}\text { PSD against PBAC } \\
\text { Correlation coef- } \\
\text { ficient } \\
\text { ( } \mathrm{p} \text { value) }\end{array}$ & $0.63(<0.003)$ & $0.09(0.83)$ \\
\hline $\begin{array}{l}\text { MD against PBAC } \\
\text { Correlation coef- } \\
\text { ficient } \\
\text { (p value) }\end{array}$ & $-0.67(0.001)$ & $0.14(0.72)$ \\
\hline $\begin{array}{l}\text { VFI against PBAC } \\
\text { Correlation coef- } \\
\text { ficient } \\
\text { (p value) }\end{array}$ & $-0.64(0.003)$ & $0.21(0.59)$ \\
\hline $\begin{array}{l}\text { NFL against PBAC } \\
\text { Correlation coef- } \\
\text { ficient } \\
\text { (p value) }\end{array}$ & $-0.25(0.16)$ & $-0.2(0.6)$ \\
\hline
\end{tabular}

n, number; PSD, pattern standard deviation; PBAC, pictorial blood assessment chart; MD, mean deviation; VFI, visual field index; NFL, average nerve fiber layer thickness 
Figure 1: Scatter plots with least square fit for the disease group
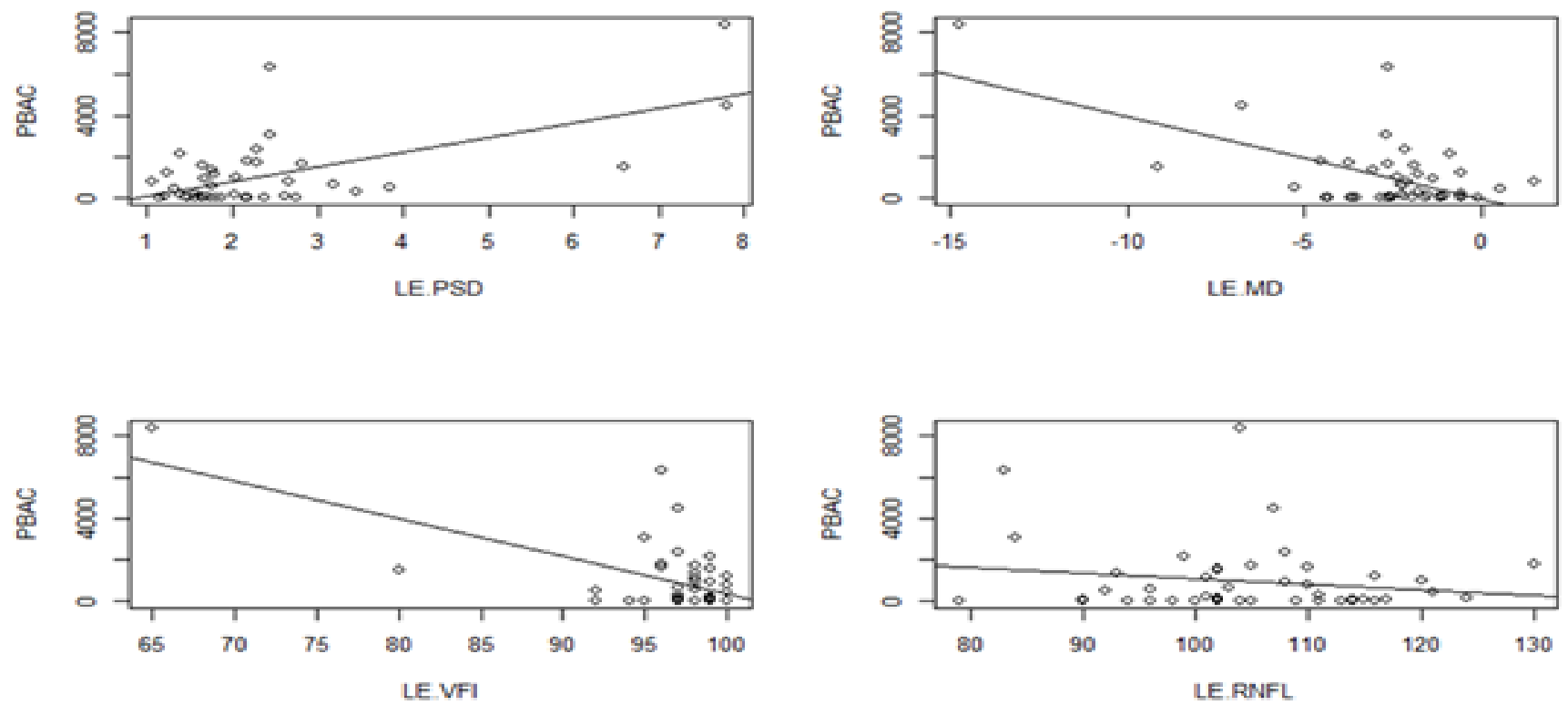

Figure 1a: Scatter plot showing a positive correlation between PBAC and left eye PSD $(p=0.009)$ Figure 1b: Scatter plot showing a negative correlation between PBAC and left eye MD $(p=0.003)$

Figure 1c: Scatter plot showing negative correlation between PBAC and left eye VFI $(\mathrm{p}=0.010)$

Figure 1d: Scatter plot showing a negative correlation between PBAC and left eye average NFL thickness $(p=0.11)$

Figure 2 Scatter plots with least square fit for all subjects
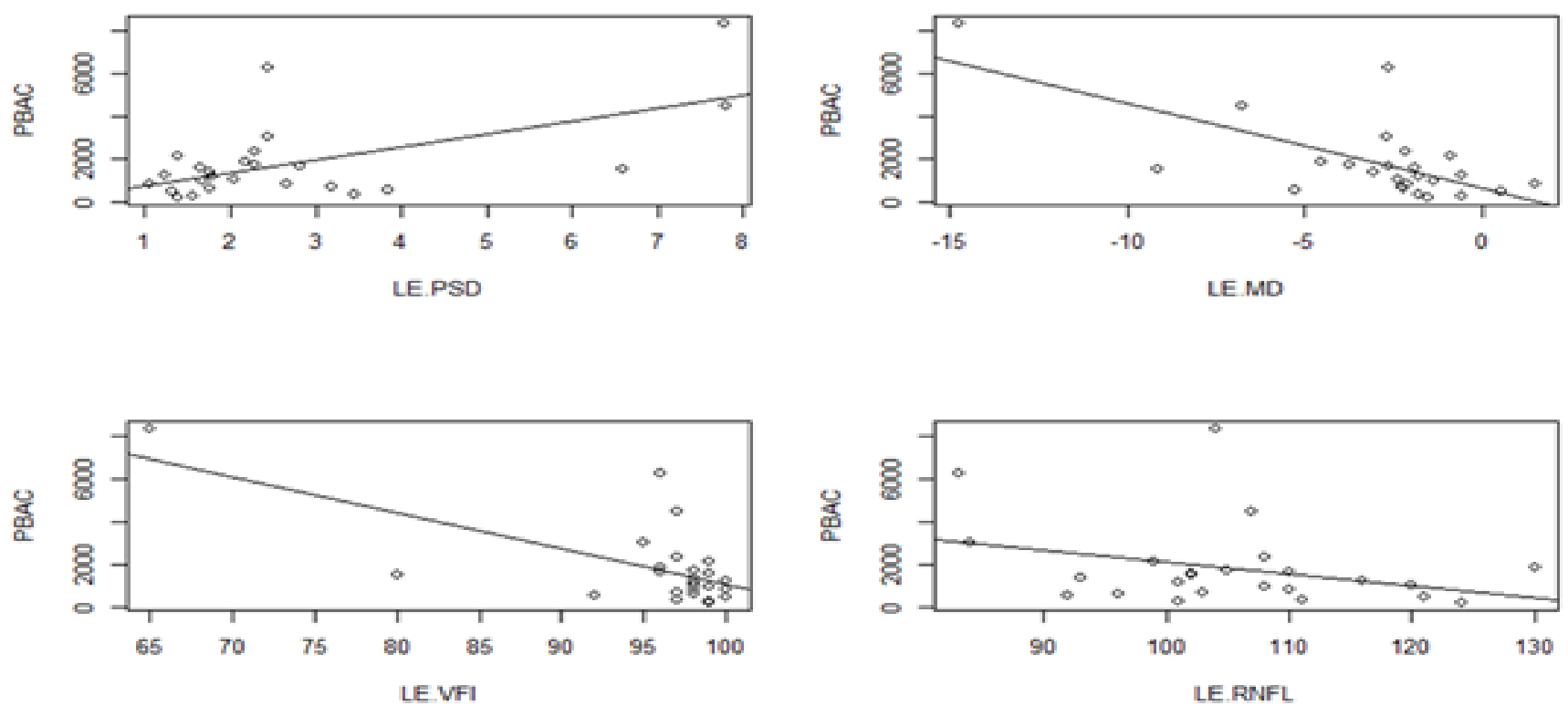

Figure 2a: Scatter plot showing a positive correlation between PBAC and left eye PSD $(\mathrm{p}<0.0001)$ Figure 2b: Scatter plot showing a negative correlation between PBAC and left eye MD $(p=0.002)$

Figure 2c: Scatter plot showing negative correlation between PBAC and left eye VFI $(\mathrm{p}=0.003)$

Figure 2d: Scatter plot showing a negative correlation between PBAC and left eye average NFL thickness $(p=0.266)$ 
The pattern of results remain unchanged, reaching statistical significance, except in control group. This is likely due the fact that only 9 subjects were analyzed. A subgroup analysis within the control group fails to show significant difference in VF performance or NFL thickness among those with normal menses and menopause. This may either be due to a small sample size. Or it could suggest that haemodynamic disturbance (menorrhagia), and not the presence or absence of menses per se, has a role in contributing to VF damage, which falls in line with previous studies showing blood flow instability as a risk factor for glaucoma [1-7,9].

When the VF global indices were compared between the disease and control group, only PSD showed a significant difference, and not MD or VFI. This may be due to PSD mainly reflecting localized loss rather than diffuse loss. Different optic neuropathies demonstrate different patterns of VF defects. Well known examples include altitudinal defects in nonarteritic and centrocaecal scotomas in toxic or nutritional neuropathies [19,20]. VF defects also vary among glaucomatous neuropathies. Superior field loss has found to been more common than inferior field loss [21]. For pigmentary glaucoma, the temporal field may be more susceptible to damage [22]. For high tension glaucoma, dense arcuate defects are more common, while for NTG, VF defects are relatively more localized and closer to fixation [11]. We have attempted studying the VF defect among the disease group; unfortunately no consensus could be drawn through analyzing our sample subjects. We postulate that a larger sample size of menorrhagia subjects, recruiting subjects with a longer duration or more severe menorrhagia may help shed light on this matter.

Vascular factors play an important role in the development and progression of optic neuropathy including glaucoma. However, the damage stems not simply from ischemia and hypoperfusion, but from blood flow instability, which the body's autoregulatory mechanism may fail to cope with. Risk factors for NTG offer a glimpse into this: vasospasm, Raynaud's phenomenon, migraine, arrhythmia and shock etc $[23,24]$. Blood flow instability gives rise to oxidative stress and repeated reperfusion injury. The increased ET1, MM9 and proteasomes particularly affect the mitochondria function of the $\mathrm{ON}$ head [3]. Reperfusion injury occurs when blood supply returns to the tissue after a period of ischemia. The absence of oxygen and nutrients from the blood creates a condition in which the restoration of circulation results in inflammation and oxidative damage through the induction of oxidative stress rather than restoration of normal function. The correlation between PBAC and VF global indices reaches statistical significance, suggesting an association between severe menorrhagia and a worse VF. However, the correlation did not reach statistical significance when ferritin and pre-transfusion haemoglobin levels were analyzed against VF indices.
We postulate two explanations for this. Firstly, although ferritin and haemoglobin levels also reflect the severity of menorrhagia, most subjects are already on iron supplements, which may confound the results. Secondly, when compared with PBAC (which directly reflects the severity of menorrhagia and thus blood flow instability), ferritin and haemoglobin levels actually reflect the severity of anaemia, a consequence of menorrhagia rather than menorrhagia itself.

Although a consistently worse VF performance was demonstrated, none of the subjects suffering from menorrhagia showed signs of glaucomatous damage when assessing the $\mathrm{CDR}, \mathrm{VF}$ and OCT. However, given the nature of reperfusion damage that menorrhagia results in and the compromised VF performance seen in our menorrhagic subjects, it is of the authors' opinion that we cannot exclude menorrhagia as a potential risk factor for developing glaucoma or glaucoma progression.

Our results are confounded by the fact that recruited subjects, although suffering from active menorrhagia, are already receiving treatment (including iron supplement and blood transfusion) to alleviate their condition. These treatments however, aim to treat the complication of menorrhagia (i.e. anaemia) and do not alter the fact that hypoperfusion had already taken place. Those suffering from severe and uncontrolled menorrhagia are likely to have undergone surgery, rendering it difficult to recruit such subjects. The mean duration of menorrhagia is also rather short (2.6 years), and glaucoma may not have developed yet at this juncture. The authors realize the relatively short duration and treated anaemia would affect how ideally our recruited subjects represent those with menorrhagia, but patients with menorrhagia are usually well looked after and seldom suffer from debilitating menorrhagia for long periods of time, rendering it difficult to study the natural course of this disease, especially in the developed country. Other weaknesses include the lack of sample size calculations and the lack of optic nerve head perfusion measurement. Being a cross-sectional study, no causality can be assumed and this study only serves as an interesting initial observation that menorrhagia subjects may have mild visual field defects. Reviewing our study design, it would be strengthened by prior sample size calculation, recruiting a larger sample size and having a prospective follow up of menorrhagia patients.

For future study direction, we suggest looking into the impact of menorrhagia on the pattern of VF defects, VF progression and whether it is a possible risk factor for glaucoma development and progression. Studies may also look into changes in ocular perfusion pressure or OCT angiography in relation to the menstrual cycle or menorrhagia. Unlike other known vascular risk factors for glaucoma like arrhythmia and Raynaud's phenomenon which are associated with other cardiovascular and autoimmune diseases, patients with menorrhagia are essentially normal healthy subjects. 
This may help us further understand the pathophysiology of glaucoma. If menorrhagia is indeed established as a risk factor for glaucoma, subjects should be warned of this risk when deciding their treatment options, and also offered regular ophthalmology checkups.

\section{Funding} Grant.

This study was funded by the Timothy Liu Memorial

\section{Acknowledgements and Competing Interests}

The authors report no conflicts of interest in this work and they have no proprietary or competing interests.

\section{References}

1) Flammer J, Orgül S, Costa VP, Orzalesi N, Krieglstein GK, et al. (2002) The impact of ocular blood flow in glaucoma. Prog Retin Eye Res 21:359-393.

2) Nicolela MT, Walman BE, Buckley AR, Drance SM (1996) Ocular hypertension and primary open-angle glaucoma: a comparative study of their retrobulbar blood flow velocity. J Glaucoma 5:308-310.

3) Mozaffarieh M, Grieshaber MC, Flammer J (2008) Oxygen and blood flow: players in the pathogenesis of glaucoma. Mol Vis14:224233.

4) Graham SL, Drance SM (1999) Nocturnal hypotension: role in glaucoma progression. Surv Ophthalmol 1:10-16.

5) Bonomi L, Marchini G, Marraffa M, Bernardi P, Morbio R, et al. (2000) Vascular risk factors for primary open angle glaucoma: the Egna-Neumarkt Study. Ophthalmology 107 :1287-1293.

6) Goldberg, Hollows FC, Kass MA, Becker B (1981) Systemic factors in patients with low-tension glaucoma. Br J Ophthalmol 65:5662 .

7) Drance S, Anderson DR, Schulzer M, et al. (2001) Risk factors for progression of visual field abnormalities in normal-tension glaucoma. Am J Ophthalmol 131:699-708.

8) Gasser P, Flammer J (1991) Blood-cell velocity in the nailfold capillaries of patients with normal-tension and high-tension glaucoma. Am J Ophthalmol 111:585-588.

9) Choi J, Kim KH, Jeong J, Cho HS, Lee CH, et al. (2007) Circadian fluctuation of mean ocular perfusion pressure is a consistent risk factor for normal-tension glaucoma. Invest Ophthalmol Vis Sci 48:104111 .

10) Anderson DR (2011) Normal-tension glaucoma (Low-tension glaucoma). Indian J Ophthalmol 59 Suppl:S97-101.

11) Araie M (1995) Pattern of visual field defects in normal-tension and high-tension glaucoma. Curr Opin Ophthalmol 6:36-45.

12) Hayreh SS, Zimmerman B (2005) Visual field abnormalities in nonarteritic anterior ischemic optic neuropathy: their pattern and prevalence at initial examination. Arch Ophthalmol 123:1554-1562.

13) Pelit A, Zumrutdal A, Akova Y ( 2003) The effect of hemodialysis on visual field test in patients with chronic renal failure. Curr Eye Res 26:303-306.

14) Drance SM, Morgan RW, Sweeney VP (1973) Shock-induced optic neuropathy: a cause of nonprogressive glaucoma. N Engl J Med 288:392-395.

15) Dunne FP, Barry DG, Ferriss JB, Grealy G, Murphy D (1991) Changes in blood pressure during the normal menstrual cycle. Clin Sci (Lond) 81:515-518.

16) Higham JM, O'Brien PM, Shaw RW (1990) Assessment of menstrual blood loss using a pictorial chart. Br J Obstet Gynaecol 97 :734739.
17) Warner PE, Critchley HO, Lumsden MA, Campbell-Brown M, Douglas A, et al. (2004) Menorrhagia I: measured blood loss, clinical features, and outcome in women with heavy periods: a survey with follow-up data. Am J Obstet Gynecol 190:1216-1223.

18) Zakherah MS, Sayed GH, El-Nashar SA, Shaaban MM (2011) Pictorial blood loss assessment chart in the evaluation of heavy menstrual bleeding: diagnostic accuracy compared to alkaline hematin. Gynecol Obstet Invest 71:281-284.

19) Atkins EJ, Bruce BB, Newman NJ, Valerie Biousse (2010) Treatment of Nonarteritic Anterior Ischemic Optic Neuropathy. Survey of Ophthalmology 55:47-63.

20) Sharma P, Sharma R (2011) Toxic optic neuropathy. Indian J Ophthalmol 59:137-141.

21) Hu S, Smith ND, Saunders LJ, Crabb DP (2015) Patterns of Binocular Visual Field Loss Derived from Large-Scale Patient Data from Glaucoma Clinics. Ophthalmology122: 2399-2406.

22) Nilforushan N, Yadgari M, Jazayeri A (2016) Comparison between visual field defect in pigmentary glaucoma and primary openangle glaucoma. International Ophthalmology 36: 637-642.

23) Gramer G, Weber BH, Gramer E (2015) Migraine and Vasospasm in Glaucoma: Age-Related Evaluation of 2027 Patients With Glaucoma or Ocular Hypertension. Invest Ophthalmol Vis Sci 56:7999-8007.

24) Drance SM (1977) The visual field of low tension glaucoma and shock-induced optic neuropathy. Arch Ophthalmol 95: 1359-1361.

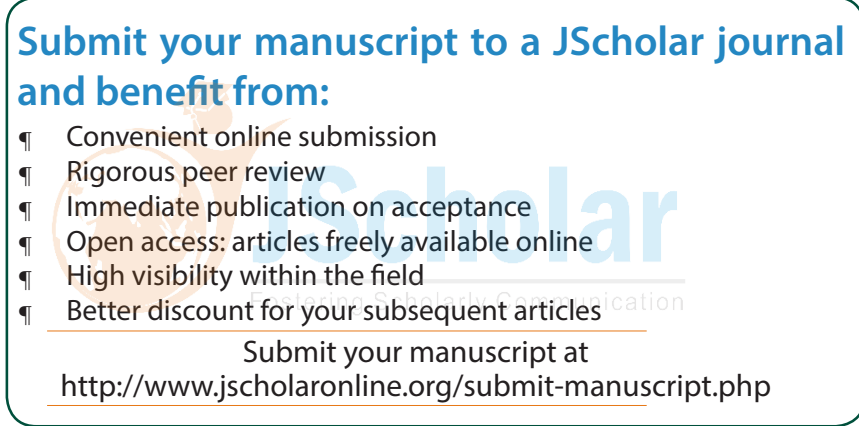

